\title{
Unusual complications of ventriculo peritoneal shunt surgery
}

\author{
Ramesh Teegala, Laxmi Prasanna Kota \\ Department of Neurosurgery, Alluri Sita Ramaraju Academy of Medical sciences (ASRAM) Hospital, ELURU, West Godavari, \\ Andhra Pradesh, India
}

\section{ABSTRACT}

Ventriculo peritoneal (VP) shunt surgery is one of the common neurosurgical procedures employed in the management of hydrocephalus. Numerous complications related to this procedure are reported in the literature. Peritoneal catheterrelated complications are the usual causes of the shunt malfunction. We report three unusual cases of peritoneal shunt catheter migration in children. Two cases are of anal and one vaginal extrusion. Possible mechanisms of migration and management strategies were discussed.

Key words: Shunt migration, anal extrusion, vaginal extrusion and endoscopic third ventriculostomy

\section{Introduction}

Ventriculo peritoneal (VP) shunt surgery is one of the standard procedures for the management of the hydrocephalus, especially in children. Despite the availability of endoscopic third ventriculostomy (ETV), VP shunting is still a common surgery done in routine practice. Abdominal complications account for about $10--30 \%$ of VP shunt procedures. ${ }^{[1,2]}$

We report two cases of trans-anal and one case of vaginal migration of the VP shunt. There is only one case of transvaginal migration reported before in the English literature. ${ }^{[3]}$

\section{Case Reports}

\section{Case 1}

A Three-year old female, who had diagnosis of tubercular meningitis (TBM) with hydrocephalus,

\begin{tabular}{|l|l|}
\hline \multicolumn{2}{|c|}{ Access this article online } \\
\hline Quick Response Code: & Website: \\
\hline & www.ruralneuropractice.com \\
\cline { 2 - 2 } & \\
\hline
\end{tabular}

underwent VP shunting by a local neurosurgeon. One and half years later, child's parents noticed shunt tube coming out of anus. [Figure 1] She reported to our emergency department with fever, neck rigidity, and refusal to feeds. On examination, the child was pale, febrile, and neck rigidity was present. On local examination, the shunt tube was seen extruding from the anus; however, there was no evidence of CSF leak from the tube.

Pre-operative biochemical evaluation showed polymorphoneuclear leukocytosis, anemia, and hypoproteinemia (total leukocyte count (TLC): 16,000 $\mathrm{mm}^{3}$; hemoglobin: $10 \mathrm{~g} / \mathrm{dl}$; serum total protein: $4.0 \mathrm{~g} / \mathrm{dl}$, albumin: $1.9 \mathrm{~g} / \mathrm{dl}$ ). The computerized tomography (CT) scan showed gross hydrocephalus.

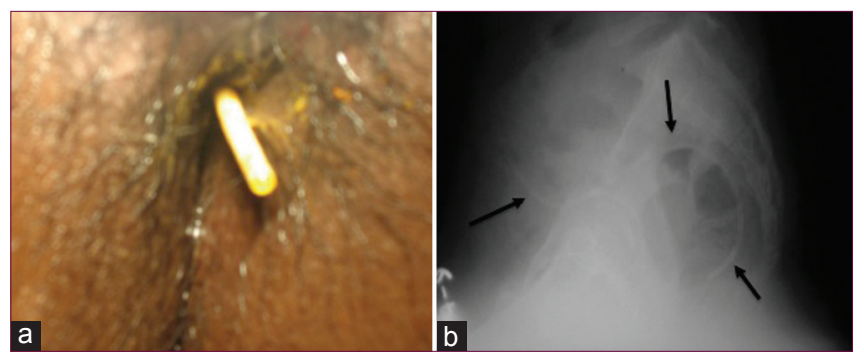

Figure 1: (a) Clinical photograph of case 1 showing the extruded shunt catheter from the anus (b) X-ray pelvis lateral view showing the shunt catheter, arrows showing the outline of the catheter along the sacral curvature.

\section{Address for correspondence:}

Dr. Ramesh Teegala, Associate Professor, Department of Neurosurgery, Alluri Sita Ramaraju Academy of Medical sciences (ASRAM) Hospital, Eluru, West Godavari, Andhra Pradesh - 534 004, India. E-mail: teegalar@gmail.com 
We did endoscopic third ventriculostomy after controlling the fever. We removed the VP shunt following the ETV. The migrated portion of the peritoneal end of the shunt tube was removed gently from anus after cutting the tube in the neck from a small incision. Remaining portions of the peritoneal catheter and ventric catheter assembly were removed through the exploration of the previous parieto occipital surgical scar. Child was kept nil by mouth for 48 hours and the child's general condition improved gradually.

Escherichia coli was grown in the shunt tip sent for aerobic culture and child was treated with culturebased antibiotics for 3 weeks and discharged in a stable condition. Follow up at 6 months showed the child was fine.

\section{Case 2}

Left side VP shunt surgery was done in a 6-year-old male child, who had the diagnosis of middle cranial fossa tumor with hydrocephalus. A local neurosurgeon operated the child one 1 year before in a different hospital, and the details of the surgical procedure are not available with the patient. The child noticed some tube like structure protruding per anum during defecation. He had no symptoms suggestive of bowel obstruction or fever. On examination, the child was asymptomatic except for the extruded VP shunt per anum. Child's family was counseled about VP shunt removal and the alternate CSF diversion procedure, which was denied by her parents and the child was lost to follow up.

\section{Case 3}

A 6-month-old female child, who had a diagnosis of Dandy Walkers malformation with hydrocephalus, underwent VP shunt two months before. Now the child developed intermittent high grade fever and her parents noticed a tube protruding per vagina. Gradually she developed refusal to feeds and neck rigidity. Operating neurosurgeon referred the child to us for further management. On examination, the child was febrile, anterior fontanel (AF) was flat, and she was having the neck rigidity. Head circumference was $41 \mathrm{~cm}$ and weighing $9 \mathrm{lbs}$. The lower end of the shunt tube was seen through the vagina with CSF dribbling from the catheter tip [Figure 2].

After preoperative evaluation and counseling, the VP shunt was removed. The migrated portion of the peritoneal end of the catheter was removed from the vagina after cutting the tube it in the neck through a small incision. Rest of the shunt system was removed through the previous perito occipital incision. As there was no gross hydrocephalus due to continuous
CSF drainage, the ETV was done after confirming the development of hydrocephalus with CT scan two days later. Cerebrospinal fluid and shunt tip showed no bacterial growth on aerobic culture.

\section{Discussion}

Hydrocephalus is common in the pediatric age group and associated with many complications. ${ }^{[4]}$ There is no ideal system for CSF diversion, and VP shunt surgery is one of the universally accepted procedures in the management of hydrocephalus. ${ }^{[4-6]}$ Numerous complications are associated with VP shunt surgery, especially with abdominal end and they include infection, CSF loculation, and cyst formation, bowel perforation, ${ }^{[5]}$ migration of the tube into pleural cavity, ${ }^{[7]}$ liver, ${ }^{[8]}$ heart, ${ }^{[9]}$ and scrotum, ${ }^{[10]}$ anus, ${ }^{[11]}$ abdominal wall, ${ }^{[12]}$ migration, and subcutaneous coiling of the peritoneal catheter, ${ }^{[13]}$ vagina, ${ }^{[3]}$ oral cavities, ${ }^{[14]}$ etc. Most of these are single case reports and trans-vaginal migration is an unusual complication.

Patel ${ }^{[3]}$ reported the first case of trans-vaginal migration in 1975 and since then, there are no fresh reports. The exact pathogenesis of the VP shunt migration through the vagina is unknown, and the possible mechanism could be that the tip of the lower end of the shunt tube might have adhered to the posterior vaginal wall in the pouch of Douglas due to inflammation. Chronic pressure by the stiff and sharp cut end of the shunt tip [Figure 2] and continuous hammer effect of the CSF pulsations could lead to the vaginal perforation. In our case (Case 3), infection and sharp tip of the shunt tube might have contributed for the perforation of vagina.

Wilson and Bertrand ${ }^{[15]}$ reported the first case of anal extrusion in 1966. Later, many cases of bowel perforation and few cases of extrusion through the anus were reported. ${ }^{[1,3-5,11,16-19]}$ Exact pathogenesis of the VP shuntrelated organ perforation is unclear. Various mechanisms have been suggested, including foreign body reaction, poor nutritional status with weakening of the intestinal

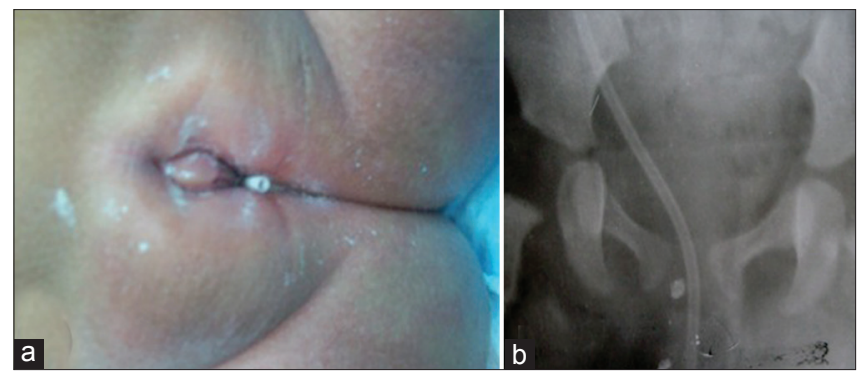

Figure 2: (a) X-ray pelvis AP image showing the shunt catheter. (b) Clinical photograph showing the shunt tip in the vagina. 
wall, and stiff end of the shunt tube causing pressure necrosis. ${ }^{\left[{ }^{619]}\right.}$ Because of weak bowel musculature, children are more susceptible to intestinal perforation..$^{[5]}$ Most cases of bowel perforation caused by peritoneal catheter occurred well after the surgery, suggesting that they resulted from a chronic inflammatory process rather than traumatic event. ${ }^{[5,17,18,20]}$ The perforation of the bowel lumen may also occur when the freely moving catheter gets adhered to the serosa of a viscus and the beveled end of the tube, coupled with continuous hammer effect of the CSF pulsations, penetrates the walls, and eventually perforate the viscus. ${ }^{[4,5]}$

In our first case, the poor nutritional status along with infection could have been the precipitating cause. No obvious precipitating factors were detected in second and third cases; however, clinical evidence of infection was seen in the third case.

The mechanism of anal extrusion is uncertain and it possibly occurs when long tubing is left in the abdominal cavity. Following the perforation due to one of the causes described above, the peristaltic waves drive the tube forward. In majority of the cases abdominal perforation is asymptomatic. A few can present with complications like intestinal obstruction, adhesion, and tube knotting, which warrant skilled management. ${ }^{[14,19,21]}$

The management of these cases is difficult and needs to be individualized. The standard method of treatment is removal of the extruded shunt system, control of infection, improvement of general condition followed by CSF diversion procedure. ${ }^{[4,5]}$

In case of asymptomatic bowel perforation with anal extrusion, part of the peritoneal portion of the tube can be removed through a small incision given over the easily palpable area in the neck. ${ }^{[4]}$ While removing the lower end of the peritoneal catheter in this manner, spillage of the bowel contents does not occur due to the formation of the mature fibrous tract around the catheter, which is attached to the bowel surface. ${ }^{[11]}$ This might be the reason for easy removal of the tube from the anus or vagina without the need for major surgical procedures like laparotomy, laparoscopy, or endoscopy. Following the shunt catheter removal, in majority of the asymptomatic bowel perforations, the perforation of the bowel was treated conservatively. ${ }^{[3,4,11,14,15]}$ In complicated cases, where removal of the shunt tubing does not occur smoothly because of knotting, twisting of the shunt tube among the bowel loops requires laparotomy. ${ }^{[4]}$ Alternatively, laparoscopy or endoscopy may be used in visualization of the shunt tubing and its disengagement. ${ }^{[14,19,21]} \mathrm{In}$ both of our cases (Cases 1 and 3), the lower end of the shunt tube was removed from the migrated orifice after cutting the tube in the neck. The remaining VP shunt hardware was removed retrograde through the cranial incision given at the time of primary surgery.

\section{Conclusion}

Hollow viscus perforation is an unusual complication of VP shunt surgery. Migration of abdominal catheter of the VP shunt through the anus or vagina is an unusual complication. The treatment of these complications includes removal of the extruded shunt, control of infection, and alternative CSF diversion procedure wherever it is required. In uncomplicated bowel perforation, the shunt tube can be removed through the migrated orifice easily and bowel perforation can be managed conservatively. In complicated cases of bowel perforation laparotomy, laparoscopy or endoscopy can help in removal of the shunt. Endoscopic third ventriculostomy is a safe and effective alternative procedure to treat the hydrocephalus following the shunt removal.

\section{References}

1. Bryant MS, Bremer AM, Tepas JJ 3rd, Mollitt DL, Nquyen TQ, Talbert JL. Abdominal complications of ventriculoperitoneal shunts. Case reports and review of the literature. Am Surg 1988;54:50-5.

2. Komolafe EO, Adeolu AA, Komolafe MA. Treatment of cerebrospinal fluid shunting complications in a Nigerian neurosurgery programme. Case illustration and review. Pediatr Neurosurg 2008;44:36-42.

3. Patel CD, Maltloub H. Vaginal perforation as a complication of ventriculoperitoneal shunt. Case Report. J Neurosurg 1973;38:761-2.

4. Handa R, Kale R, Harjai MM. Unusual complication of Ventriculoperitoneal Shunt: Anal extrusion. Medical Journal Armed Forces IndiaMJAFI 2007;63:82-4.

5. Jang HD, Kim MS, Lee NH, Kim SH. Anal extrusion of distal V-P shunt catheter after Double perforation of large intestine. J Korean Neurosurg Soc 2007;47:232-4.

6. Jindal A, Kansal S, Mahapatra AK. Unusual complication-VP Shunt coming out per rectum and brain abscess. Indian J Pediatr 1999;66:463-5.

7. Johnson MC, Maxwell MS. Delayed intrapleural migration of a ventriculoperitoneal shunt. Childs Nerv Syst 1995;11:348-50.

8. Thipphavong S, Kellenberger CJ, Rutka JT, Manson DE. Hepatic and colonic perforation by an abandoned ventriculoperitoneal shunt. Pediatr Radiol 2004;34:750-2.

9. Kim BJ, Cha SH, Park DJ, Song GS, Choi CH, Lee YW. A case of intra cardiac migration of distal ventriculo-peritoneal (V-P) shunt catheter. J Korean Neurosurg Soc 2000;29:270-3.

10. Selcuklu A, Pasaoglu A, Akdemir H, Kurtsoy A, Kavuncu I. Migration of the peritoneal catheter of a ventriculoperitoneal shunt in to the scrotum. Case report. Turk Neurosurg 1991;2:52-3.

11. Gupta SK, Jaiswal AK, Kumar S. Ventriculoperitoneal shunt catheter masquerading as ascariasis. J Clin Neurosci 2005;12:967-8.

12. Wakai S. Extrusion of peritoneal catheter through the abdominal wall in an infant. Case report. J Neurosurg 1966;57:148-9.

13. Agarwal A, Kakani A. Shunt malfunction due to proximal migration and subcutaneous coiling of a peritoneal catheter. J Neurosci Rural Pract 2010;1:120-1. 
14. Sridhar K, Karmarkar V. per oral extrusion of ventriculoperitoneal shunt: Case report and review of literature. Neurol India 2009;57:334-6.

15. Wilson CB, Bertrand V. Perforation of bowel complicating peritoneal shunt for hydrocephalus. Report of two cases. Am Surg 1966;32:601-3.

16. De Aquino HB, Carelli EF, Borges Neto AG, Pereira CU. Nonfunctional abdominal complications of the distal catheter on the treatment of the hydrocephalus: An inflammatory hypothesis? 'Experience with six cases'. Childs Nerv Syst 2006;22:1225-30.

17. Digray NC, Thappa DR, Mengi Y, Goswamy HL. Silent bowel perforation and trans anal prolapse of a ventriculoperitoneal shunt. Pediatr Surg Int 2000;16:94-5

18. Esposito C, Porreca A, Gangemi M, Garipoli V, De Pasquale M. The use of laparoscopy in the diagnosis and treatment of abdominal complications of Ventriculo-Peritoneal shunts in children. Pediatr Surg Int 1998;13:352-4.
19. Yousfi MM, Jackson NS, Abbas M, Zimmerman RS, Fleischer DE. Bowel perforation complicating ventriculoperitoneal shunt: Case report and review. Gastrointest Endosc 2003;58:144-8.

20. Di Rocco C, Marchese E, Vellardi F. A survey of the first complication of a newly implanted CSF devices for the treatment of non tumoral hydrocephalus. Childs Nerv Syst 1994;10:321-7.

21. Sharma A, Pandey AK, Radhakrishnan M, Kumbhani D, Das HS, Desai N Endoscopic management of anal protrusion of ventriculo-peritoneal shunt. J Gastroenterol 2003;22:29-30.

How to cite this article: Teegala R, Kota LP. Unusual complications of ventriculo peritoneal shunt surgery. J Neurosci Rural Pract 2012;3:361-4. Source of Support: Nil. Conflict of Interest: None declared. 